\title{
Network analysis can guide resilience-based management in forest landscapes under global change
}

\author{
Marco Mina (D) 1,7 Christian Messier, ${ }^{1,2}$ Matthew Duveneck, ${ }^{3,4}$ Marie-Josée Fortin, ${ }^{5}$ And Núria Aquilué (DD 1,6 \\ ${ }^{1}$ Centre for Forest Research (CEF), Université du Québec à Montréal (UQAM), succursale Centre-Ville, Montréal, \\ H3C 3 P8 Quebec Canada \\ ${ }^{2}$ Institut des Sciences de la Forêt Tempérée (ISFORT), Université du Québec en Outaouais (UQO), 58 Rue Principale, \\ Ripon, J0V1V0 Quebec Canada \\ ${ }^{3}$ Harvard Forest, Harvard University, 321 North Main St., Petersham, 01366 Massachusetts USA \\ ${ }^{4}$ Liberal Arts Department, New England Conservatory, 290 Huntington Avenue, Boston, 02115 Massachusetts USA \\ ${ }^{5}$ Department of Ecology and Evolution, University of Toronto, 25 Willcocks Street, Toronto, M5S3G5 Ontario Canada \\ ${ }^{6}$ InForest Joint Research Unit, Forest Sciences and Technology Centre of Catalonia (CTFC), Ctra. Sant Llorenç de Morunys, \\ km 2, Solsona 25280 Spain
}

Citation: Mina, M., C. Messier, M. Duveneck, M.-J. Fortin, and N. Aquilué. 2020. Network analysis can guide resilience-based management in forest landscapes under global change. Ecological Applications 00(00):e02221. 10.1002/eap.2221

\begin{abstract}
Forests are projected to undergo dramatic compositional and structural shifts prompted by global changes, such as climatic changes and intensifying natural disturbance regimes. Future uncertainty makes planning for forest management exceptionally difficult, demanding novel approaches to maintain or improve the ability of forest ecosystems to respond and rapidly reorganize after disturbance events. Adopting a landscape perspective in forest management is particularly important in fragmented forest landscapes where both diversity and connectivity play key roles in determining resilience to global change. In this context, network analysis and functional traits combined with ecological dynamic modeling can help evaluate changes in functional response diversity and connectivity within and among forest stands in fragmented landscapes. Here, we coupled ecological dynamic modeling with functional traits analysis and network theory to analyze forested landscapes as an interconnected network of forest patches. We simulated future forest landscape dynamics in a large landscape in southern Quebec, Canada, under a combination of climate, disturbance, and management scenarios. We depicted the landscape as a functional network, assessed changes in future resilience using indicators at multiple spatial scales, and evaluated if current management practices are suitable for maintaining resilience to simulated changes in regimes. Our results show that climate change would promote forest productivity and favor heat-adapted deciduous species. Changes in natural disturbances will likely have negative impacts on native conifers and will drive changes in forest type composition. Climate change negatively impacted all resilience indicators and triggered losses of functional response diversity and connectivity across the landscape with undesirable consequences on the capacity of these forests to adapt to global change. Also, current management strategies failed to promote resilience at different spatial levels, highlighting the need for a more active and thoughtful approach to forest management under global change. Our study demonstrates the usefulness of combining dynamic landscapescale simulation modeling with network analyses to evaluate the possible impacts of climate change as well as human and natural disturbances on forest resilience under global change.
\end{abstract}

Key words: forest ecology; forest landscape modeling; forest management; functional diversity; global change; LANDIS-II; natural disturbances; network analysis; resilience.

\section{INTRODUCTION}

Global environmental changes and socio-economic pressures are affecting forest ecosystems at an increasingly rapid pace (Weed et al. 2013, Millar and Stephenson 2015, Seidl et al. 2017). In particular, uncertainty due to global change such as climate warming, shifts in societal

Manuscript received 19 March 2020; revised 13 May 2020; accepted 29 June 2020. Corresponding Editor: Yude Pan.

${ }^{7}$ E-mail: mina.marco@courrier.uqam.ca expectations, and intensifying natural disturbance regimes is challenging forest management planning (Keenan 2015, Vilà-Cabrera et al. 2018). Managers generally rely on historical reference conditions to manage forest stands. To maintain provisioning of a few services, mostly timber, forest structures and communities are simplified and forest practices standardized (Puettmann et al. 2009). However, future environmental conditions are highly uncertain and traditional approaches may be ineffective for managing forests to increase resistance and adaptive capacity (Seastedt et al. 2008). As such, many researchers 
have suggested that new principles and approaches like adaptive silviculture (Halofsky et al. 2016), climate-smart forestry (Nabuurs et al. 2017), and functional zoning (Messier et al. 2009) should be used.

One way to maintain or improve the ability of forest ecosystems to respond to sudden changes and at the same time sustain sufficient levels of ecosystem functions or services is to manage for resilience (Messier et al. 2013, Fahey et al. 2018). This approach represents a paradigm shift away from traditional silvicultural methods: the maximization of rapid self-reorganization and the diversification of ecosystem functions are actively integrated into management strategies across multiple temporal and spatial scales (Seidl et al. 2016). An efficient resilience-based management, however, requires a flexible multi-scale perspective (e.g., from stand to management area to landscape) and the consideration of multiple processes in relation to the globally changing socio-ecological conditions (Messier et al. 2016).

Embracing a landscape perspective is especially important in regions where forest ecosystems have been reduced from large woodlands to smaller fragmented patches (Foster et al. 1998). These are usually the most inhabited regions of the planet and where society strongly relies on forest-based ecosystem services (Mitchell et al. 2014). In these human-transformed scattered landscapes, network theory, the study of graphs representing systems of discrete interconnected objects, can be applied to evaluate effective connectivity between forest patches (Ricotta et al. 2000, Dale and Fortin 2010). High potential dispersal among patches ensures a rapid tree recolonization of disturbed stands by seeds coming from the surrounding intact stands, contributing to a swift and efficient reorganization of the system. Additionally, methods based on functional traits can be used to evaluate functional response diversity and functional redundancy within forest stands and across landscapes (Aubin et al. 2016, Nock et al. 2016). Functional traits are biological characteristics influencing species performance in terms of growth, survival, or reproduction (Violle et al. 2007). Describing forest communities not only in terms of tree species but according to specific traits for adapting to climate change and coping with disturbances (i.e., response traits) allows characterizing ecosystem adaptation and resilience to known stressors. A functionally diverse community is composed of species with a high mixture of response traits enabling the ecosystem/forest to functionally persist despite disturbances (Mori et al. 2013). Functional redundancy refers to the number of species contributing in a similar way to an ecosystem function (Laliberte et al. 2010). High functional redundancy therefore implies high recurrence of traits within a community, which would make such community highly adaptable as loss of individual species following unexpected disturbances would not compromise overall ecosystem functioning (Yachi and Loreau 1999, Thompson et al. 2009). Hence, functional connectivity (LaPoint et al. 2015; in our case, the potential seed dispersal of species and traits across and/or among patches), functional response diversity, and functional redundancy are suitable indicators for evaluating landscape-level ecological resilience in fragmented forest ecosystems (Craven et al. 2016, Aquilué et al. 2020).

The combined use of functional diversity and network analysis applied to forest management has been recently proposed (Messier et al. 2019). With this approach, a forested landscape is represented as a functional network, describing the spatial distribution and topology of forest stands while accounting for functional diversity at multiple spatial scales. The fundamental units of a functional network are nodes, in our case, forest patches/stands with different levels of functional diversity, and links, denoting the amount of functional connectivity among nodes. Important nodes with a number of links that greatly exceeds the average are called hubs while nodes contributing to connectivity between two or more highly connected groups of nodes are known as module connectors (Delmas et al. 2019). This approach assesses the likelihood of functional diversity dispersion across the network according to seed dispersal capacity and proportion of intra-patch functional diversity between nodes (Craven et al. 2016). Using network analysis and resilience-proxy indicators such as functional response diversity, redundancy and connectivity, silvicultural practices at the stand/ownership scale can be evaluated and coordinated at a landscape and regional level to enhance resilience (Messier et al. 2019). Since it is typically not feasible to intervene everywhere across large landscapes due to logistics and limited resources, planning interventions in limited strategic areas or stands is critical (Aquilué et al. 2020).

Because of the high uncertainty related to global changes, dynamic simulation models can be extremely valuable for evaluating future scenarios at multiple scales, and to support management decisions for adapting forests to global changes (Fontes et al. 2010, Seidl et al. 2013, Shifley et al. 2017). Recent studies using principles of the functional complex network on forest landscapes used static methods and stressed the urgent need for integrations with dynamic modeling to take into account the temporal component of forest dynamics and to directly link tree establishment, growth, and mortality to changing environmental drivers (Aquilué et al. 2020). Here, we couple a dynamic simulation model, accounting for processes at multiple spatial scales, nonlinear relationships, long-term temporal scale, and ecological drivers of forest change, with network analysis and functional diversity methods to demonstrate how such an approach can guide forest management to increase forest resilience at multiplescales.\#AuthorQueryReply\#

Focusing on a fragmented forest landscape in southern Quebec (Canada), our specific objectives are (1) to assess long-term impacts of climate change and disturbances on forest productivity and composition, (2) to evaluate changes in resilience-related properties (functional diversity, redundancy, connectivity) at multiple spatial scales, and (3) to evaluate the effectiveness of current 
management in maintaining forest resilience to expected changes. We hypothesize that (1) a warmer climate would promote forest productivity and favor heat-adapted temperate deciduous species at the expense of cold-adapted boreal species, and that (2) climate change and disturbances would have negative impacts on resilience indicators at multiple spatial scales (Duveneck and Scheller 2016, Lucash et al. 2017). Finally, we hypothesize that (3) currently practiced forest management would not foster resilience in such fragmented landscapes.

\section{Materials And Methods}

\section{Study area}

The study area includes the entire Centre-du-Québec, a large administrative region in southern Quebec, Canada $\left(45^{\circ} 35^{\prime}-46^{\circ} 34^{\prime} \mathrm{N}, 72^{\circ} 59^{\prime}-71^{\circ} 22^{\prime} \mathrm{W}\right.$, Fig. 1). This 692,600-ha landscape is located between the northern extent of the Appalachians Mountains and the St. Lawrence River. The climate is humid continental, with a large seasonal temperature range (mean temperature: annual $5.1^{\circ} \mathrm{C}$, January $-11.7^{\circ} \mathrm{C}$, July $19.5^{\circ} \mathrm{C}$ ) and annual precipitation partitioned between rainfall (mean $861 \mathrm{~mm} / \mathrm{yr}$ ) and snowfall (mean $232 \mathrm{~cm} / \mathrm{yr}$ ). The vegetation is typical of the Mixedwood Plains and Atlantic Maritime terrestrial ecozones (Marshall et al. 1996), which transitions from northern hardwood forests to mixedwood with southern boreal conifers (Table 1). The most abundant tree species are red maple (Acer rubrum), sugar maple (Acer saccharum), balsam fir (Abies balsamea), and yellow birch (Betula alleghaniensis). Historic and recent forest management has had a strong impact on forest structure and composition; compared to presettlement conditions, forests are generally younger and have a higher share of deciduous pioneers (Dupuis et al. 2011). Forest covers $51 \%$ of the area $(355,300 \mathrm{ha})$ and is extremely fragmented by agricultural land and humanmade infrastructures (Fig. 1). Forestry is a major industry in the region and many ecosystem services in addition to timber production are dependent on the forest (e.g., maple syrup production, biodiversity, habitat conservation, and recreation). Many stands are timber plantations, mostly of spruce (e.g., Picea glauca, Picea mariana, Picea rubens, Picea abies) and pine species (e.g., Pinus resinosa, Pinus strobus). The land is primarily privately owned (93\%) and is subdivided into five Regional County Municipalities (RCM; hereafter our management area unit).

\section{Simulation modeling}

We used the forest landscape model LANDIS-II v7.0 (Scheller et al. 2007) to project forest dynamics in the Centre-du-Québec. LANDIS-II is a widely used model that simulates forest successional processes, seed dispersal, regeneration, growth, and mortality, in interconnected grid cells, integrating stand- with landscape-level processes driving forest landscape dynamics. LANDISII is built on a core module interacting with multiple extensions, each simulating succession, disturbances, or management at various levels of complexity. Trees are grouped into species-age cohorts in each cell. To simulate forest succession, we used the PnET-Succession v3.4 extension (de Bruijn et al. 2014). This extension is based on algorithms of the PnET-II ecophysiological model (Aber et al. 1995) and simulates the competition among cohorts for water and light at a monthly time step as a function of photosynthetic processes that are explicitly linked to environmental drivers such as temperature, precipitation, photosynthetically active radiation (PAR), and $\mathrm{CO}_{2}$ concentration. Regeneration depends on distance from a seed source, soil water, and subcanopy light, while competition is modeled by partitioning incoming light through multiple canopy layers. Growth of specific cohort biomass components (e.g., root, foliage, wood, non-structural carbon) increases with foliar $\mathrm{N}$, and atmospheric $\mathrm{CO}_{2}$ concentration. Growth decreases as cohorts approach their longevity age but mortality can occur at any time when carbon reserves production is insufficient to support growth due to shading, water competition, and/or drought (Gustafson et al. 2015). Model documentation of LANDIS-II and its extensions as well as executables and model source code are available online. ${ }^{8}$

\section{Model initialization}

Forest composition was initialized using a combination of forest stand maps and data from 2,834 permanent and temporary forest inventory plots (MFFP 2017) in the province of Quebec. We performed a nearestneighbor spatial imputation based on six stand predictor variables (density, height, age, species composition, species assemblage, main canopy cover) to attribute the most similar inventory plot to each raster cell. Ecoregions within the landscape were classified as subregions sharing similar climatic conditions and soil types. We carried out a calibration on the most influential model parameters of PnET-Succession (see McKenzie et al. 2019) by comparing initial simulated biomass against biomass maps derived from inventory records. Model initialization and calibration is described in detail in Appendix S1. We ran simulations of forest dynamics for a period of $91 \mathrm{yr}$ (2010-2100, both inclusive) across $>330,000$ forested cells at $100-\mathrm{m}$ resolution.

\section{Climate scenarios}

We considered three climate futures: current climate, moderate emission, and high emission scenarios. For current climate, we projected a continuation of normal climate conditions until 2100 by imputing a randomly selected year from the historical time series 1960-2000

\footnotetext{
${ }^{8}$ http://www.landis-ii.org/
} 


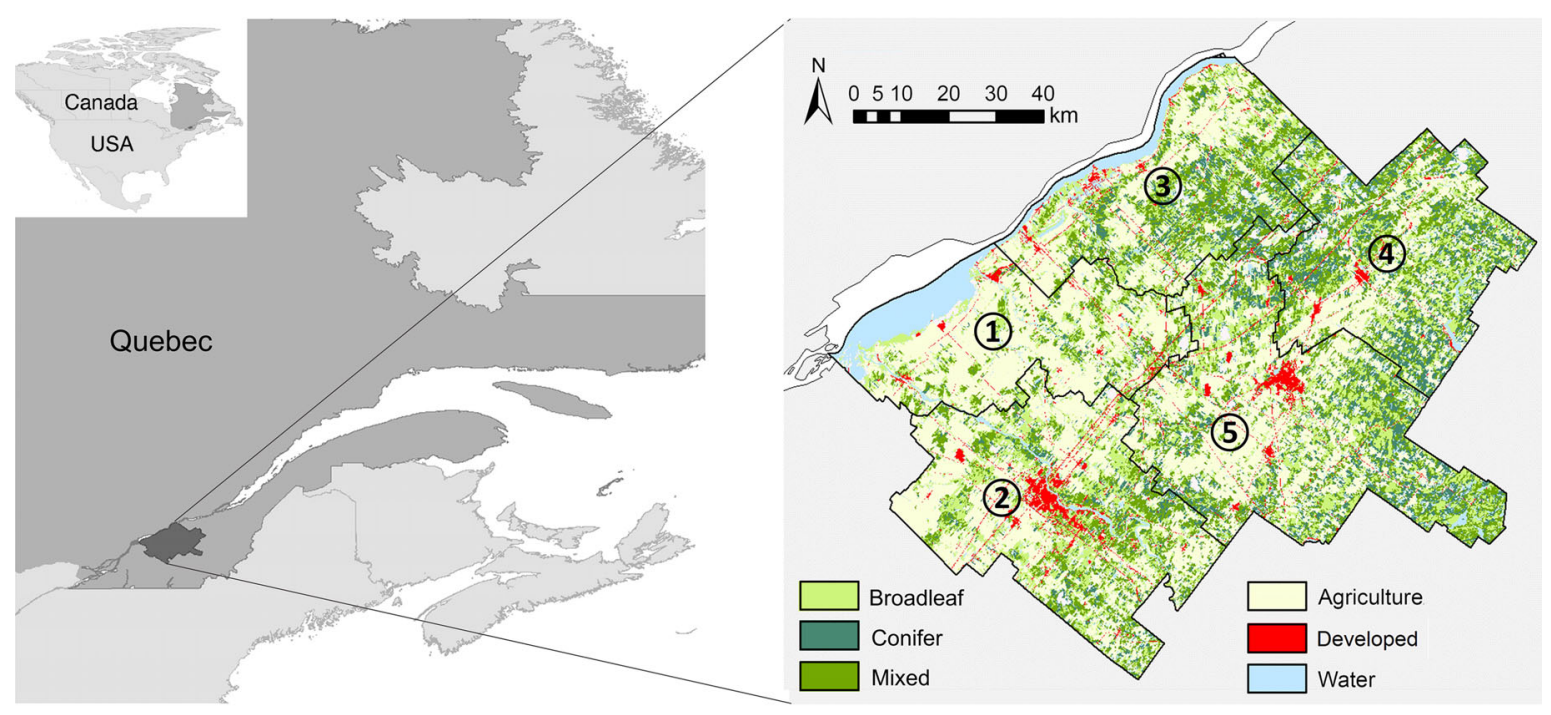

FIG. 1. On the left, geographical location of the study area within North America and the Canadian province of Quebec. On the right, the Centre-du-Québec subdivided into the five Regional County Municipalities: 1, Nicolet Yamaska; 2, Drummond; 3 , Becancour; 4, L’Erable; 5, Arthabaska.

TABLE 1. Common names of selected tree species and the initial (2010) percentage of aboveground biomass (AGB).

\begin{tabular}{lc}
\hline \hline Species & AGB $(\%)$ \\
\hline Red maple & 31.9 \\
Sugar maple & 12.6 \\
Balsam fir & 10.3 \\
Yellow birch & 7.1 \\
Eastern hemlock & 6.3 \\
Northern white cedar & 5.9 \\
Quaking aspen & 4.1 \\
White spruce & 3.6 \\
Eastern white pine & 3.1 \\
Black spruce & 2.2 \\
Tamarack & 2.0 \\
Red spruce & 2.0 \\
American beech & 1.6 \\
Red pine & 1.5 \\
Paper birch & 1.4 \\
Gray birch & 1.4 \\
Bigtooth aspen & 1.3 \\
White ash & 1.0 \\
Norway spruce & 1.0 \\
\hline
\end{tabular}

Note: Scientific names, species codes, functional traits, and model parameters are given in Appendix S2: Table S1.

derived from meteorological stations in the region (ECCA 2019) and from recent global carbon dioxide concentration measurements. Climate change scenarios employed the Regional Concentration Pathway (RCP) 4.5 (moderate) and 8.5 (high) emission scenario from the IPCC (IPCC 2013) as simulated by the Canadian Earth System Model version 2 (CanESM2; Arora and Boer 2010) global circulation model. Climate projections were downscaled for the Centre-du-Québec and made available by the Innovation Cluster on Regional Climatology Ouranos (Ouranos 2015). Additional details on the climate scenarios are given in Appendix S1. The moderate and high emissions scenarios include a mean annual temperature increase of approximately $5^{\circ}$ and $8.5^{\circ} \mathrm{C}$, respectively, throughout the study area by 2100 (compared to the reference period 1961-2000). Simulated annual precipitation for each climate change scenario would increase only slightly from current values (Appendix S1: Fig. S6).

\section{Management and natural disturbance scenarios}

We used the Biomass-Harvest v4.3 extension (Gustafson et al. 2000) to simulate both harvesting and natural disturbances. The extension selects and removes biomass based on user-defined prescriptions, determining cohorts that should be removed as well as the percentage of the area suitable for harvesting/removal at each time step within a harvesting area. We simulated a business-asusual (BAU) management regime using harvest guidelines from the Forestry Agency of Bois-Francs (Agence forestière des Bois-Francs, AFBF). This agency coordinates the financial and technical support to private forest owners and is responsible for developing sustainable forest management guidelines for the Centre-du-Québec (AFBF 2015). Information on harvesting regimes implemented independently by private forest owners (i.e., without the agency's support) were not available so we assumed that all private forests in Centre-du-Québec are being managed following the guidelines of the agency. We defined harvesting areas using the agency's map of private and public ownership combined with a map 
locating sugar-maple-dominated stands (Appendix S1: Fig. S8). Silvicultural prescriptions by stand structure (even-aged, uneven-aged) and forest types (conifer plantations, mixed stands, hardwoods) were applied in both private and public forests, except for sugar bushes, where harvesting was simulated with a distinct prescription that encourages the maintenance of sugar maple over other tree species, and for public forest reserves (no harvesting).

The Biomass-Harvest extension was also used to simulate a scenario of generic natural disturbance by implementing cohort mortality events across the landscape. Removal of cohort biomass due to increased mortality was based on species-specific scores expressing the vulnerability of tree species to an ensemble of disturbances and stressors (e.g., disease, insects and pests, browsing, invasive species, ice, wind, fire, pollution; see Appendix S1: Table S2). Scores were obtained from Matthews et al. (2011) and Brandt et al. (2017) in the context of the Climate Change Tree Atlas project (Prasad et al. 2007). Natural disturbance scores were rescaled from 1 to 10 and averaged to obtain one overall vulnerability index per species that was then used to derive proportions of cohort(s) biomass removal. Mortality events were simulated randomly across $5 \%$ of the landscape's area at each time step (5 yr), allowing spatial spreading up to 30 ha (see Appendix S1). The percentage of landscape affected at each time step was held constant throughout the simulation time (i.e., did not interact with climate change) and biomass removals affected cohorts of all ages equally.

For each climate future, we simulated three management-disturbance scenarios: CONTROL (no management nor disturbance), BAU (current management, no disturbance), and BAU-DIST (current management + disturbance). Since variability among model runs was minimal (maximum variance of species biomass at year 2100 was $3.548 \%$ for 5 replicates and $3.549 \%$ for 10 replicates), we simulated 5 replicates for each scenario for a total of 45 simulations ( 3 climate scenarios $\times 3$ management-disturbance scenarios $\times 5$ replicates). We assessed temporal trends in total and specieslevel aboveground biomass (AGB), monthly net primary productivity and changes in species assemblages (forest types) using the Biomass Reclassification extension v3.0.

\section{Functional network}

We computed the functional network at each time step of the simulations under each climate, harvesting, and disturbance scenario. Following the method presented in Aquilué et al. (2020), we represented the forested landscape as a functional network using the principles of functional traits and diversity (Nock et al. 2016) and graph theory (Ricotta et al. 2000, Urban and Keitt 2001). We used the initial communities map with species AGB for 2010 to determine forest patches applying an eight-neighbor rule (see Appendix S1). Nodes of the network were defined as forest fragments larger than 5 ha while large forest patches $(>1,500 \mathrm{ha})$ were further clustered in smaller patches based on differences in main forest type (conifers vs. deciduous) and geographical coordinates. Next, we built a complete direct graph with $n=1,249$ patches (average area $=267 \pm 428 \mathrm{ha}$, mean \pm SE), with in-degree and out-degree (i.e., the number of links incoming to or outgoing from a node) of all nodes equal to $n-1$, and links accounting for the effective minimum Euclidean distance between patches calculated from patch border. To calculate the functional response diversity of the tree communities, we selected eight functional traits associated with responses of species to disturbances and environmental change. We focused on response traits directly related to resistance to stressors such as drought, shade, and waterlogging, and those related to regeneration after disturbance such as maximum tree height, wood density, mode of reproduction, seed mass, and seed dispersal vector. Functional trait values were obtained from the literature (Niinemets and Valladares 2006, Miles and Smith 2009, Aubin et al. 2012) and from species parameters used in LANDIS/PnET-Succession (Appendix S2: Table S1). Functional response diversity of each network node was quantified using the abundance-weighted functional dispersion index (Laliberté and Legendre 2010), which accounts for how functionally different the species are from one another in a community and is mathematically independent of species richness. The index was computed using a generalization of Gower's distance (Pavoine et al. 2009), and the lingoes correction was applied to obtain a Euclidean functional dissimilarity matrix. Links between nodes were calculated based on the distance between forest patches, species composition, presence of mature trees able to produce seeds, and species seed dispersal capacity (Appendix S2: Table S1). Connections between nodes occurred if at least one tree species could disperse to its maximum seed dispersal distance. Links were directional (e.g., from patch a to patch b but not necessarily vice versa) and weighted proportionally to the intensity of the connection $\left(W_{a b}\right)$, that is the functional diversity that can travel from the source to the target node $\left(W_{a b}=\right.$ FDIS $_{a b} / \mathrm{FDIS}_{a}$ where $\mathrm{FDIS}_{a b}$ the functional diversity calculated for those species in node $a$ that can disperse to node $b$; (Barrat et al. 2004)). The result was a directional weighted graph with 1,249 nodes, each characterized by a different level of functional diversity (Appendix S2: Fig. S1). Since we did not simulate land-cover changes (e.g., forest plantations in agricultural land, rural abandonment, urbanization of forest areas), network structures were directly comparable across scenarios.

To quantify network properties and assess differences between scenarios, we calculated functional response diversity, functional redundancy, and functional connectivity at both the landscape (Centre-du-Québec) and management area level (RCM). Functional response diversity and functional redundancy were measured as 
the functional dispersion index and functional redundancy index (Laliberté and Legendre 2010, Ricotta et al. 2016), while functional connectivity was computed as the probability of connectivity index PC following Saura and Pascual-Hortal (2007). The three indicators were rescaled as a percentage, using initial conditions (2010) as a reference. All calculations were performed in $\mathrm{R}$ version 3.6.1 (R Core Team 2019) using multiple packages including FD (Laliberté and Legendre 2010), cluster, dplyr, raster, and igraph (Csardi and Nepusz 2006).

\section{RESUlTS}

\section{Climate, management and natural disturbance effects on forest productivity and composition}

Our simulations indicated a general increase in total tree aboveground biomass (AGB) across the landscape. Total AGB increased with increasing anthropogenic climate forcing but at a lower magnitude once the effects of management and natural disturbances were considered (Fig. 2). Greater AGB under climate change from increased simulated net primary productivity (NPP) is due to more favorable growth conditions (higher temperatures and $\mathrm{CO}_{2}$ concentration). Compared to current climate, NPP under climate change in 2100 was greater in spring (April, May) and autumn (October, November) but lower during the summer months. This indicates a longer growing season under climate change but potential drought-related stress due to increased respiration in July and August (Fig. 3).

Within forest types, climate change resulted in a higher proportion of northern hardwoods and less of an increase in boreal conifers. Pioneers, pines, and other conifers under climate change resulted in similar patterns to current climate (Fig. 4). Harvesting generally favored northern hardwoods and exotic conifers while only slightly reducing the increase of boreal conifers. Natural disturbances, however, resulted in a strong reduction of boreal conifers. The spatial distribution of forest types in 2100 showed a clear increase in boreal conifers in areas previously dominated by other conifers and pioneers under the current climate scenario $\mathrm{CON}$ TROL (Appendix S2: Fig. S3). Increasing climate change and natural disturbances, however, resulted in a clear dominance of northern hardwoods and a decline in boreal conifers across the entire region, particularly in the northeastern areas (Appendix S2: Fig. S3).

For individual species, we found substantial differences in simulated $\mathrm{AGB}$ and responses to climate change, forest management, and natural disturbances (Fig. 2 and Appendix S2: Fig. S2). Pioneer species, shade-intolerant birches and poplars, were projected to decline no matter the simulated scenario, although these species made up a small proportion of the landscape to begin with. This was likely due to increased effects of competition with late successional species, which showed a general increase in AGB over time. In response to climate change, some species (e.g., maples, hardwoods, tamarack, pines) showed an increase in AGB while others declined, particularly under high emissions (e.g., balsam fir, eastern hemlock, red and black spruce). We did not detect large differences in patterns of species dynamics between the CONTROL and the BAU scenarios across climate futures. AGB reductions were also observed in some species (e.g., balsam fir, black spruce, and yellow birch) when natural disturbances were simulated in addition to harvesting.

\section{Temporal and multi-spatial changes in the functional network}

At the landscape scale, functional response diversity (FDiv) was projected to decrease over time under most climate, management, and natural disturbance scenarios (Fig. 5). Climate change further induced FDiv reduction, especially at the end of the high emission future. Although this indicator decreased under most scenarios, FDiv declined less when natural-induced disturbances were considered (BAU-DIST) under moderate and high emissions, and it was maintained at initial levels only under current climate. On the other hand, functional redundancy (FRed) increased over the simulation time but only marginally (max $0.58 \%$ under Current-CONTROL). Similar to FDiv, FRed was negatively affected by changes in climatic conditions; by the end of each simulation, FRed leveled off under moderate emissions and declined under high emissions (Fig. 4). The temporal pattern of FRed was nearly identical for the CONTROL and the BAU scenarios, but, different from FDiv, revealed a reduction when natural disturbances were considered (BAU-DIST). Functional connectivity (FConn) declined under most simulated scenarios, with a reduction up to $-45 \%$ in 2100 compared to initial conditions (High-CONTROL). Only under current climate, harvesting and natural disturbances (Current-BAU-DIST) this indicator increased slightly. Climate change negatively affected FConn and the differences between climate scenarios diverged more under human and natural-induced disturbances (BAU, BAU-DIST).

Although FDiv decreased under most scenarios, we observed spatial differences in its simulated pattern across the entire landscape (Fig. 6). For example, under the CONTROL-current scenario, FDiv mostly decreased on fragmented patches found in the northwestern and central parts of the landscape. Increasing climate and natural disturbance pressures, however, resulted in a reduction in FDiv also in larger, well-connected stands found in the northeastern part of the landscape. Despite the overall decline, FDiv increased locally in a number of small fragmented, often disconnected, stands across the landscape (nodes $>0.1 \%$ in Fig. 6; Appendix S2: Fig. S4). The northeastern and eastern portions of the landscape had high FConn among patches; despite extended losses, numerous connections 


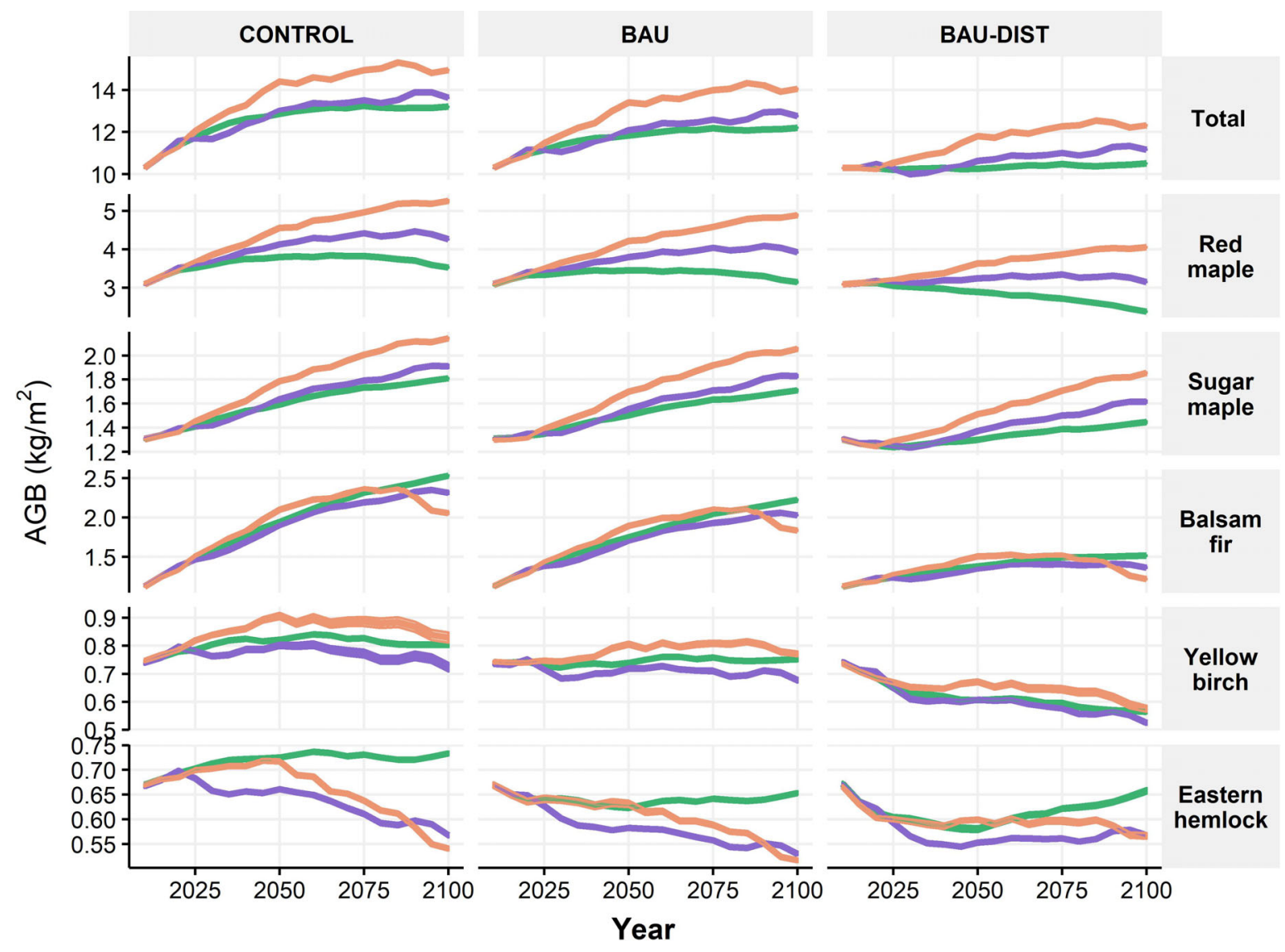

\section{Climate 日 Current $\mathrm{日}$ Moderate $\mathrm{G}$ High}

FIG. 2. Aboveground biomass (AGB, $\mathrm{kg} / \mathrm{m}^{2}$ ) of all species (Total) and for the five most abundant species $(68 \%$ total AGB in 2010) for 91 simulated years (2010-2100) across the Centre-du-Québec under the nine climate change, management and natural disturbances scenarios. Ribbons show the marginal standard deviation between the five model runs (for most species, the standard deviation is too low to observe; exceptions include yellow birch in the Control scenario). BAU, business as usual; BAU-DIST, business as usual + disturbance.

were projected to be maintained. The western and central portions of the landscape, however, showed a great reduction in links under most scenarios. Harvesting and disturbances resulted in preserving some connections that were lost under the CONTROL scenario, but these were observed only under the current climate scenario (Fig. 6; Appendix S2: Fig. S4).

We identified clear differences between the impact of climate change and natural disturbances for the three indicators at the management area scale (RCMs; Fig. 7). For some RCMs (Arthabaska, L'Erable), differences in FDiv between climate scenarios were only minor while in others (Nicolet-Yamaska, Drummond) high climate change triggered substantial reductions. For all five management areas, there were essentially no differences in simulated FDiv between CONTROL and BAU, while FDiv was higher under BAU-DIST in Nicolet-Yamaska and Drummond, but only under current climate. While functional redundancy (FRed) increased at the landscape scale, there were several differences among the five
RCMs depending on the scenarios. Under the CONTROL scenario, FRed increased between $0.42 \%$ and $0.70 \%$ in all five management areas with current climate; when high climate change was considered, however, FRed increased only by $0.07 \%$ in Nicolet-Yamaska and Becancour, and $0.05 \%$ in Drummond. Harvesting and natural disturbances further intensified these differences, with RCMs Drummond and Becancour having a negative difference in 2010-2100 FRed under BAU-DIST and high emissions. RCMs that were not affected by a strong reduction in FDiv were those with a larger decrease in functional connectivity. This was particularly evident under the CONTROL scenario, showing reductions up to $-39.7 \%$ for L'Erable under high emissions. Under harvesting, FConn reductions were lower but still negative in all management areas under climate change (-32.8\% L'Erable and $-26.2 \%$ Drummond under high emissions). Under harvesting and natural disturbances, FConn increased in all RCMs under current climate (up to $19 \%$ in Nicolet-Yamaska and Drummond) but still 


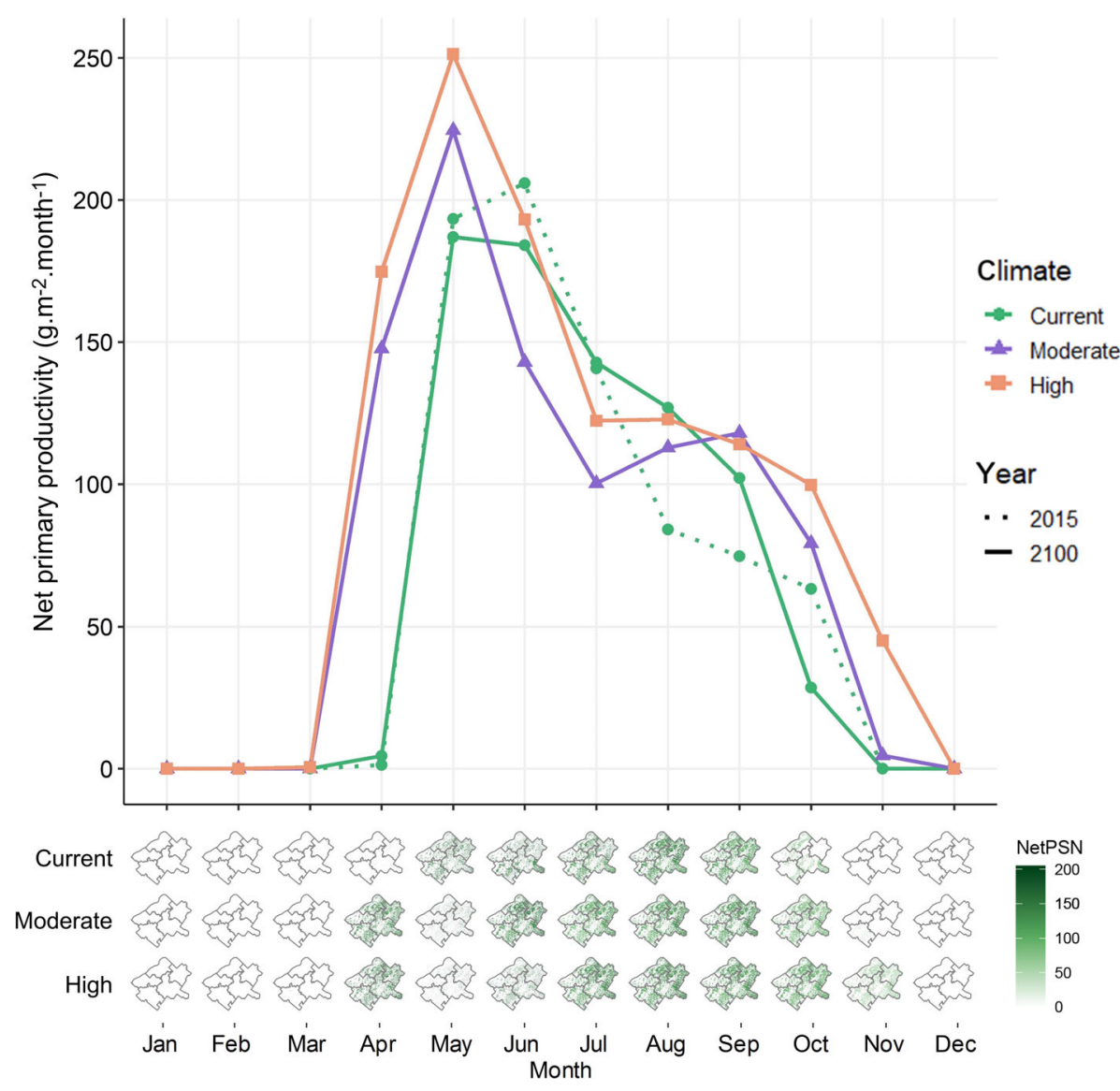

FIG. 3. Simulated monthly net primary productivity of all species in the Centre-du-Québec after the first time step (2015, dotted line) and at the end of the 21 st century (2100, solid line) under current, moderate and high climate forcing scenarios. The maps show how monthly NPP varied spatially across the landscape and management areas depending on the simulated climate scenario in 2100. Data shown for the management scenario BAU.

declined under high emissions (up to $-15.3 \%$ in L'Erable).

The identification of spatial changes in FDiv and FConn among nodes (i.e., stands) in sub-portions of the landscape (Fig. 8) was achieved through an analysis of the functional network structure at the management area scale. For example, in Drummond, although FDiv was not projected to decrease drastically under $\mathrm{CON}$ TROL-current scenario (Fig. 8a), network analysis showed a large reduction in FConn, resulting in a landscape increasingly fragmented functionally. Above all, functional connectivity was projected to be lost or to be decreased in intensity between hubs (i.e., large nodes connecting many small nodes) and many smaller, outer nodes (Fig. 8a, inset). Under high emissions and natural disturbances, FDiv declined in several large, connecting nodes, but despite this, in certain zones, connectivity with outer nodes was locally maintained (Fig. 8c). In the RCM L'Erable, FDiv did not decrease dramatically but an extensive reduction in connectivity was observed, particularly between the northwest and southeast; by 2100 , this resulted in a forested landscape functionally fragmented in two (Fig. 8b). Under high emissions and natural disturbances, the northwest portion of this management area showed extensive reductions in FDiv in large and well-connected nodes (Fig. 8d).

\section{Discussion}

Our study demonstrates how dynamic landscape-scale simulation modeling can be coupled with network analysis and tree species functional traits to evaluate how the interactions of climate change, forest management and natural disturbances affect forest succession and resilience at multiple scales.

Our results confirm our first hypothesis that climate change would promote forest productivity and favor heat-adapted deciduous species (i.e., hardwoods) at the expense of boreal conifers in our target region. However, findings also reveal a higher sensitivity of conifers to natural disturbance factors, which may be more relevant than warming in driving changes in forest type dominance within the landscape. Our findings validated the first part of our second hypothesis that climate change 


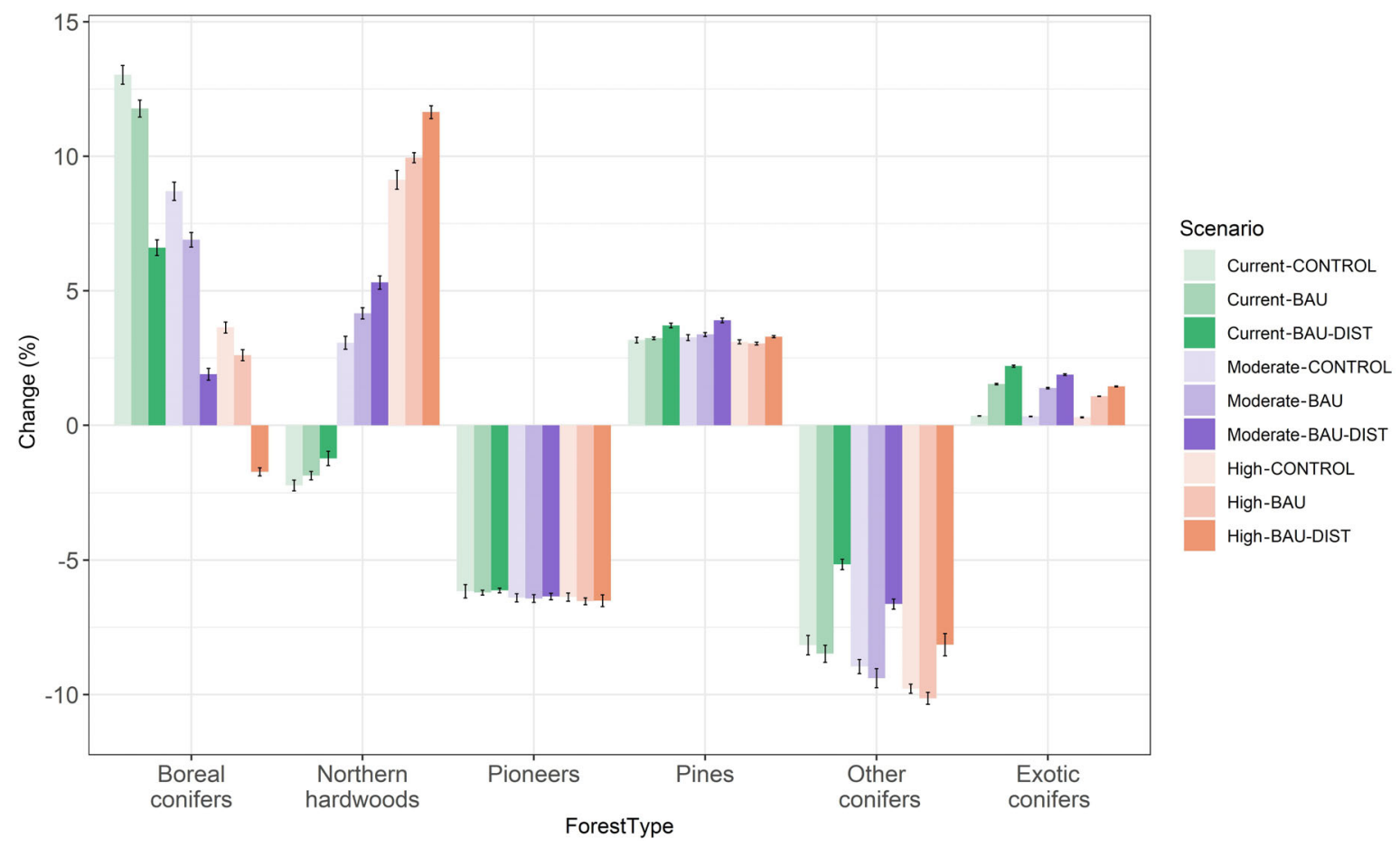

FIG. 4. Change in forest type dominance in 2100 compared to initial conditions (2010) for the nine climate change, management and natural disturbance scenarios expressed as a percentage. Error bars show the standard deviation across the five model runs.

would have a negative impact on resilience indicators at the landscape level, but did not confirm the second part regarding the negative impact of natural disturbances on all resilience indicators. Additionally, different patterns were detected at the management area and local scales, highlighting the need for a multi-scale perspective when evaluating resilience in forest landscapes. Finally, our results confirmed that current management strategies are not effective in maintaining functional diversity and connectivity. This emphasizes the need to develop forest management strategies to foster resilience and adaptability of forest landscapes to global change (Dymond et al. 2014, Hof et al. 2017, Messier et al. 2019).

\section{Future forest dynamics, productivity, and species composition}

In the absence of natural disturbances, our results project that forests in southern Quebec will increase in total AGB across the 21st century irrespective of the climate scenario. These findings corroborate other studies in which northeastern American forests are still in the process of recovering from historical land use and are currently below their maximum biomass capacity (Thompson et al. 2011, Duveneck et al. 2017, Wang et al. 2017, Barton and Keeton 2018). Climate change further promoted forest biomass gain, particularly under high emissions. Climate scenarios indicate rising temperatures combined with moderate increases in annual precipitation; in our simulations this resulted in longer growing seasons and greater forest biomass. Despite potential positive implications for ecosystem services such as carbon sequestration and forest-based industry, excessive warming may cause growth declines, particularly when interacting with specific biotic disturbance agents (Anderegg et al. 2015). A reduction in cold temperatures and decline in snowpack could affect the ecology of these forests, boosting the proliferation of forest insect pests and browsers such as deer, with negative impacts on water, soil, and wildlife, and related ecosystem services (Contosta et al. 2019). Also rapid changes in the growing season may induce phenological mismatches in several species, with early bud break and delay in leaf senescence leaving trees exposed to late and early frost damage, respectively (Frank et al. 2017). Our results also showed a general reduction in NPP in the summer months. Duveneck and Thompson (2017) found similar patterns for forests in New England, suggesting that in the long term these temperate forest ecosystems might be prone to drought stress, which may occur independently of taxonomic differences (Martin-Benito and Pederson 2015). Although in our simulations higher spring and autumn NPP compensated for the decrease in summer NPP, more frequent and extreme heat events during summer could lead to changes in growth patterns. For instance, intra-annual growth patterns may shift from unimodal to bimodal, typical for sub-Mediterranean ecosystems (Camarero 

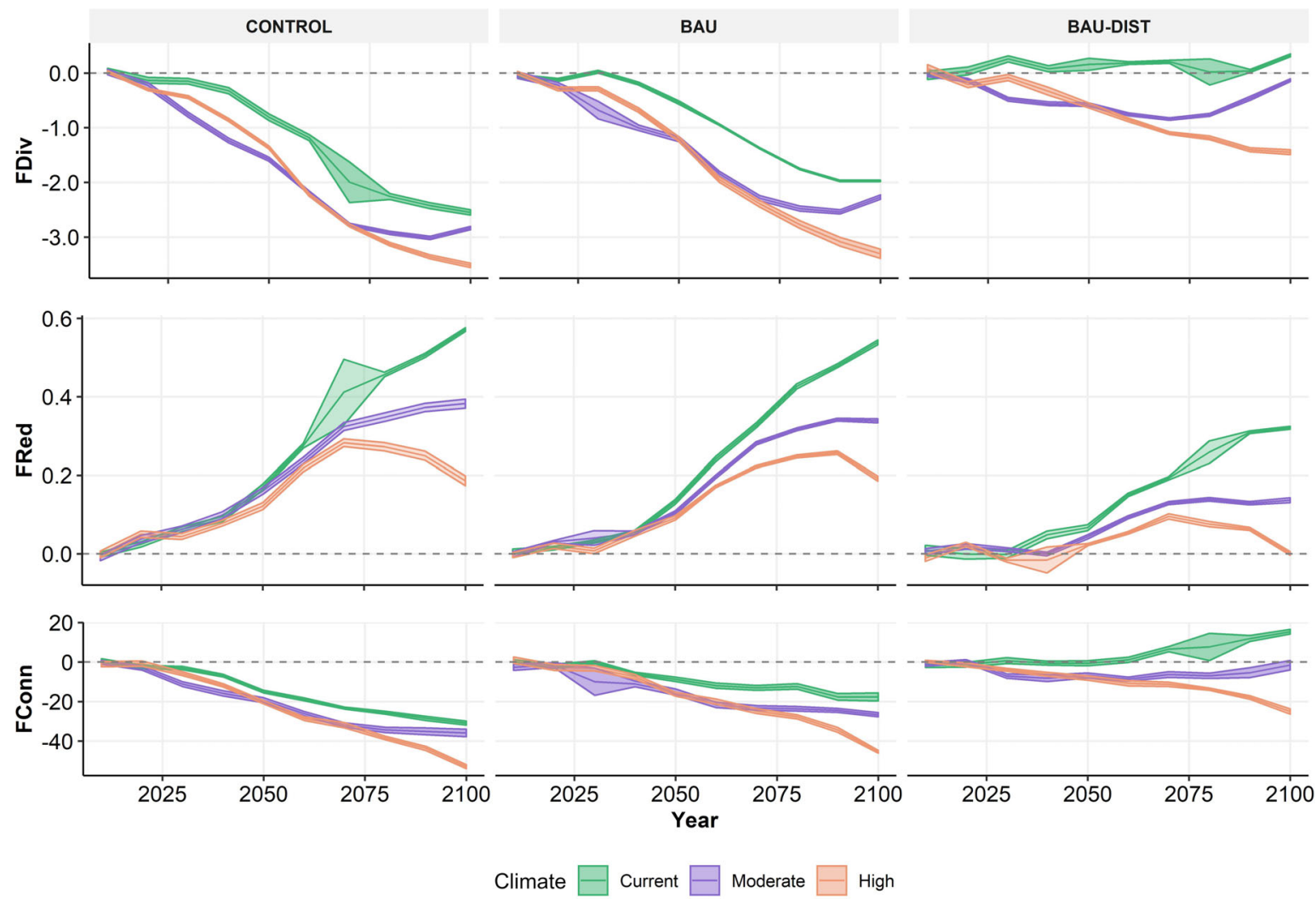

FIG. 5. Changes in functional response diversity (FDiv), functional redundancy (FRed), and functional connectivity (FConn) at the landscape level under all scenarios expressed as a percentage. Ribbons, where apparent, show the standard deviation between the five model runs.

\section{Current-Control}

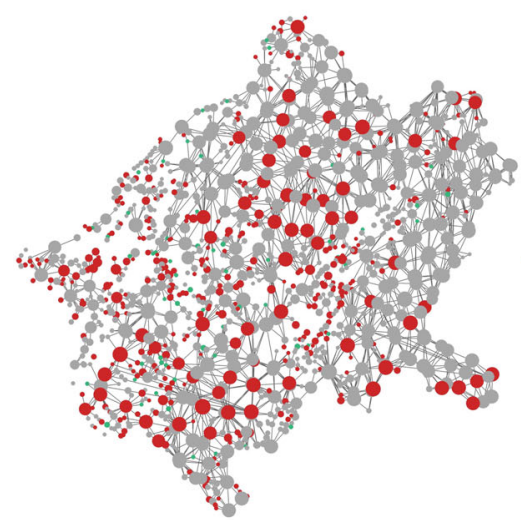

Moderate-BAU

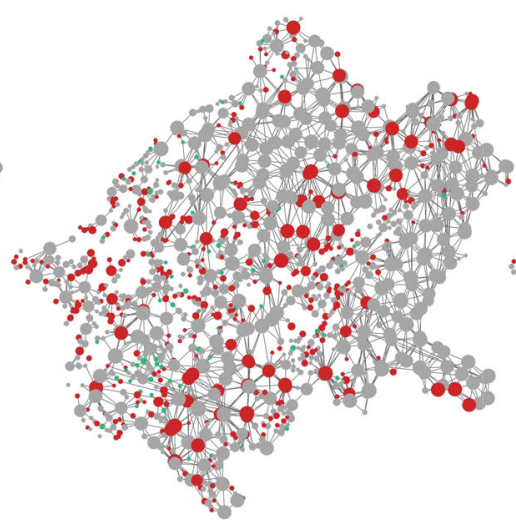

High-BAU-DIST

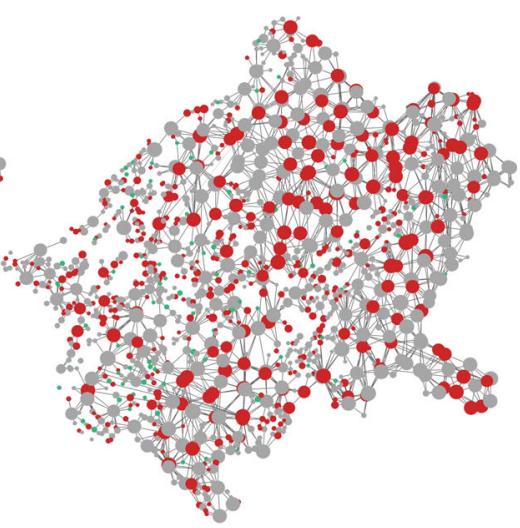

FDiv $\bigcirc<0 \quad \bigcirc 0-0.1 \quad \bigcirc>0.1 \quad$ Links $\longrightarrow 2010 \rightarrow 2100$

FIG. 6. Centre-du-Québec as a functional network under three climate change, management and natural disturbance scenarios. Node colors indicate change 2010-2100 of FDiv (ranging between -0.21 and +0.25 ). Light gray arrows, when visible, indicate initial links (in 2010) while dark gray arrows indicate links maintained, or newly established, by 2100 . Node size is proportional to patch area. Results are shown for one model run. The remaining six scenarios are shown in Appendix S2: Fig. S4.

et al. 2010), and the pace of seasonal change might be too fast for phenological adaptations for some species (Housset et al. 2015).
Total AGB showed a reduction when tree mortality events due to natural disturbances were simulated in combination with current climate, but increased climate-induced 

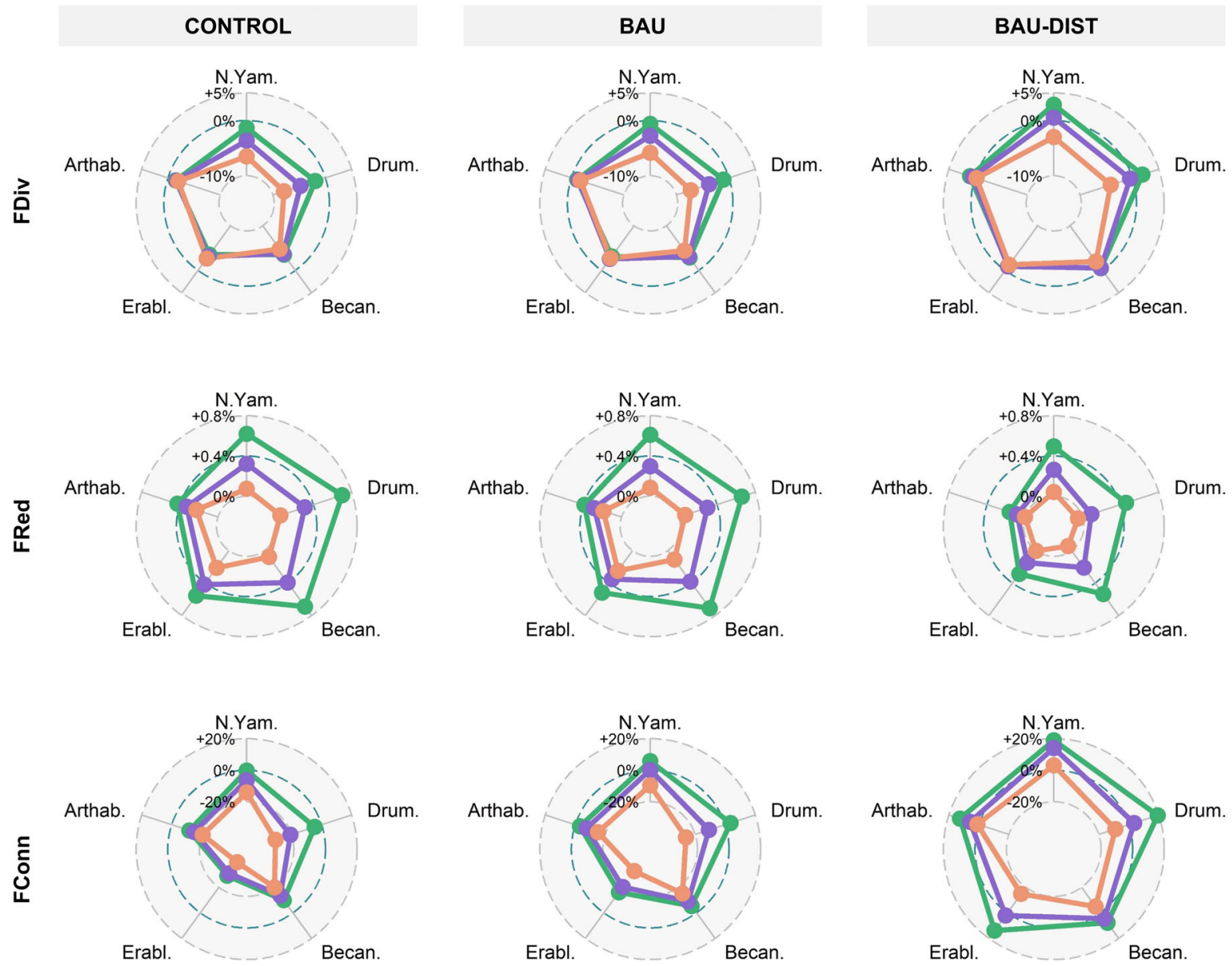

Climate $\longrightarrow$ Current $\longrightarrow$ Moderate $\longrightarrow-$ High

FIG. 7. Changes 2010-2100 of functional response diversity (FDiv), functional redundancy (FRed), and functional connectivity (FConn) for the five management areas (RCM Nicolet-Yamaska [N.Yam.], Drummond [Drum.], Becancour [Becan.], L'Erable [Erebl.], and Arthabaska [Arthab.] expressed as a percentage; see map in Fig. 1). Values displayed are means among the five model runs.

growth potential compensated for this decrease. This effect was particularly clear for the two most abundant species influencing total AGB (red and sugar maple), but it was not a trend observed in all other species present in the region. For some species (e.g., balsam fir, Eastern hemlock, black spruce), the combined effect of high climatic changes and disturbances resulted in the lowest AGB at simulation end. Our natural disturbance pressure was held constant throughout the simulations and did not interact with changing climate. Several studies, however, have shown that the combined effect of climate warming and increasing disturbances would likely result in significant reductions in forest productivity and carbon storage (Gauthier et al. 2015, Seidl et al. 2017, Boucher et al. 2018).

Within forest types, our results suggest that climate change and natural disturbances will likely promote northern hardwoods to the detriment of boreal conifers in such northern temperate forest transition zones.
Although our simulations did not report very drastic reductions in boreal conifers, results are in line with several field and modeling studies that demonstrate that boreal species will likely be more vulnerable to a warmer climate when growing at the southern edge of their ecological distribution (Fisichelli et al. 2014, Girardin et al. 2016, Boulanger et al. 2017). Modeling studies conducted in New England indicated an increase in dominance of northern pines and hardwoods and decreases in sprucefir associations under climate change, but overall showed modest effects on forest composition (Duveneck et al. 2017). In our simulations, pine growth was projected to be enhanced by climate warming but the increase in pinedominated forest type areas was only modest. A possible explanation is that across our landscape, pine is mostly present as monospecific timber plantations and does not have a high chance of regenerating and increasing in mixedwood stands unless aided by targeted silvicultural 

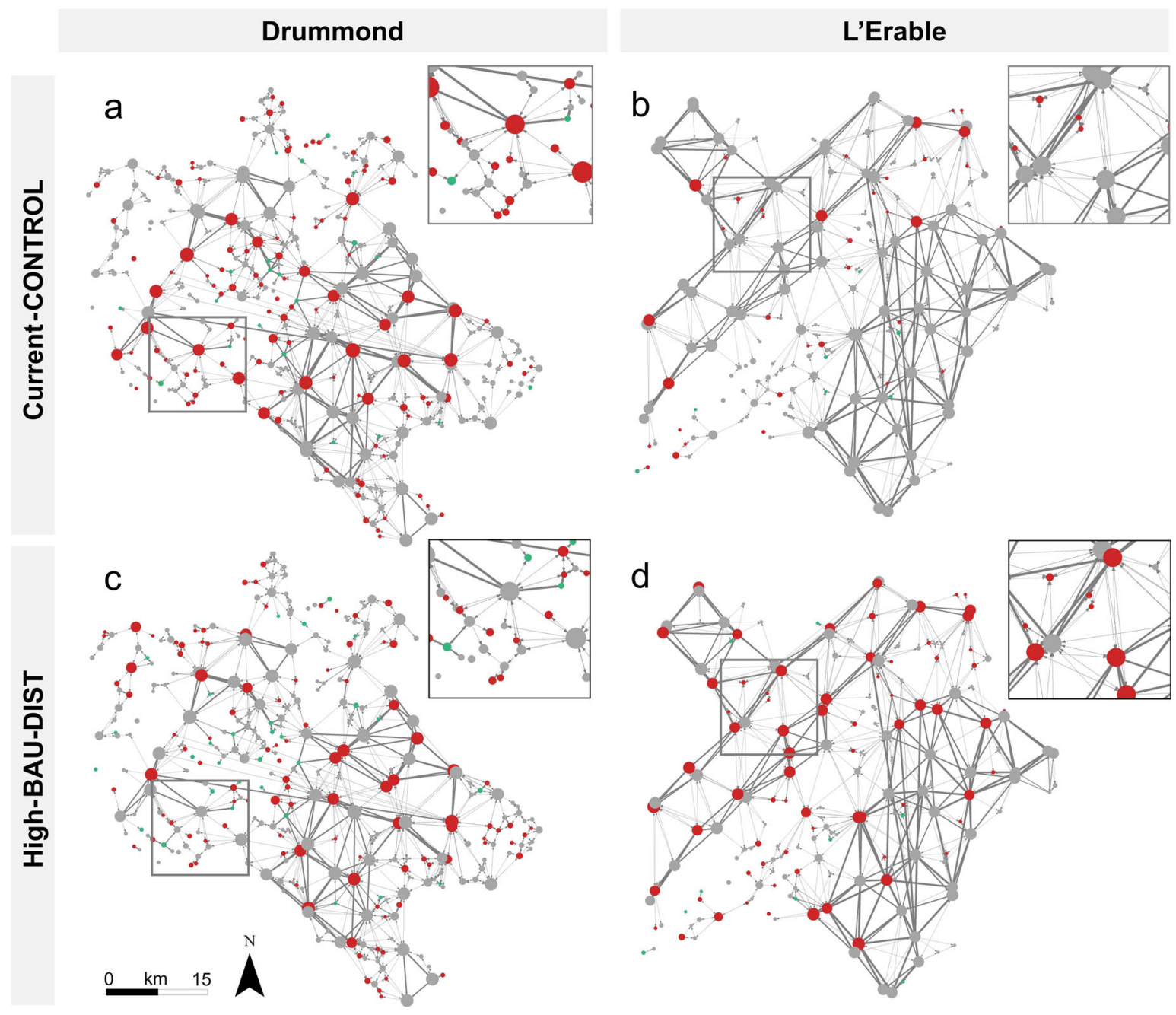

$$
\text { FDiv } \bigcirc<0 \quad 0 \quad 0-0.1 \quad \bigcirc>0.1 \quad \text { Links } \longrightarrow 2010 \rightarrow 2100
$$

FIG. 8. Two management areas represented as functional networks under two simulated scenarios. Node colors indicate simulated change 2010-2100 in functional response diversity. Light gray arrows show node links at simulation start. Dark gray arrows show links maintained, or newly established, at simulation end. Node size is proportional to patch area and link's width proportional to the intensity of the connection. Insets zoom in on a specific area of the landscape to depict changes in FDiv and FConn at the stand level. Results are shown for one model run.

systems (Raymond et al. 2006). Of course, the ultimate response to climate and treatment on our system is masked by the longevity of the tree species present and the fact that the treatment effects largely damaged cohorts rather than cause mortality. More substantial responses to tree composition are expected beyond 2100 after cohorts die and new regeneration occurs.

\section{Resilience properties of the functional network at multiple scales}

Supporting the first part of our second hypothesis, climate change was found to have negative impacts on all resilience indicators. This suggests that the increasing dominance of some species at the expense of others, as described above, is related to a loss of vital functional traits, resulting in a decline in functional response diversity and functional redundancy. This may have important consequences on the capacity of these forests to adapt following unexpected disturbances, as these two properties are key determinants of ecosystem resilience in the face of global change uncertainty (Elmqvist et al. 2003, Mori et al. 2013). Also, the capacity of these forests to rapidly recolonize and efficiently self-reorganize might be hampered by potentially decreased functional connectivity, which is an additional key attribute 
contributing to resilience in such fragmented landscapes (Craven et al. 2016, Beller et al. 2018).

Natural disturbances, instead, had a positive effect on functional diversity and connectivity. Simulated tree mortality events prompted canopy opening and large gaps; therefore, more light was projected to be available on the ground and in the understory. This likely enabled the establishment and growth of shade intolerant species, carriers of valuable functional traits, and therefore promoted functional diversity. This suggests that moderate disturbances are important for maintaining species and functional diversity at multiple scales (Biswas and Mallik 2010, Willig and Presley 2018). The modest increase due to simulated natural disturbance was evident only under current climate but not enough to improve or maintain current levels of functional response diversity and connectivity under climate change. The mild positive effect of simulated natural disturbances on resilience indicators was nullified by the negative impact of climate change. This implies that if global emissions are not rapidly reduced and climate warming does not slow down, strategic management interventions including increased harvesting of most dominant species and enrichment planting would be needed to counteract this trend (Dymond et al. 2014, Duveneck and Scheller 2015, Messier et al. 2019). Contrarily, simulated natural disturbances reduced the modest increase in functional redundancy. As demonstrated in several studies, this indicator is a suitable proxy for resilience to unexpected disturbance because the impact of the loss of an individual species within a tree community is reduced if there are multiple species with analogous traits performing similar functions (Yachi and Loreau 1999, Pillar et al. 2013). In our simulation study, random mortality events by natural disturbances had a different effect on each species depending on the vulnerability indices. This explains why functional redundancy, the number of species performing similar functions, thus sharing similar traits, was negatively affected under this scenario. This is consistent with results by Aquilué et al. (2020), who found that simulated pest outbreaks reduced functional redundancy at the landscape scale. Yachi and Loreau (1999) proposed functional redundancy as an effective indicator of ecosystem resilience to disturbance. However, a community that only maximizes the number of species performing similar functions might not be resilient enough at the occurrence of severe, wide-scale, stand-replacing disturbances (e.g., hurricanes or catastrophic fires extirpating all trees from an area). In this case, a community that optimizes not only functional redundancy but functional response diversity and connectivity as well, is likely to have higher post-disturbance performance (Correia et al. 2018). Thus, multiple resilience indicators evaluated at multiple spatial scales are needed when assessing forest ecosystem resilience (Seidl et al. 2013, Standish et al. 2014).

While the effect of climate change and natural disturbance on resilience indicators shows a clear landscape trend, the picture is more intricate at the management area and stand levels. For example, the structure and the composition of some RCMs (Arthabaska and L'Erable), make them less prone than others to losses in functional diversity and redundancy. This is likely because such areas did not experience drastic losses in species composition, and therefore traits, due to climate change and disturbance in our simulations (although still experiencing losses in functional connectivity). Traditionally, forest management planning has emphasized a single spatial and/or decisional scale (e.g., forest enterprise, management unit). From a management perspective, adopting such a multi-scale approach could allow managers (for example, across the five management areas in our landscape) to compare features between contiguous management areas, determine specific levels of functional diversity, redundancy and connectivity found in more resilient landscapes, and replicate these levels in less resilient landscapes (Messier et al. 2013, Puettmann and Tappeiner 2013).

Although averages of the three indicators at landscape and management area level are useful for identifying temporal trends, network analysis at the node level allows detecting changes in resilience properties at the stand scale (see Fig. 8). For example, in the highly fragmented management area of Drummond, the average functional diversity decreased but at the stand level this attribute increased in several small and less connected nodes. Such stands probably do not require any specific silvicultural intervention (e.g., enrichment planting, favoring rare traits) to enhance resilience. However, other stands or nodes that were more greatly affected in terms of functional diversity could be managed to increase functional diversity. If the latter are hubs and connectors, management that promotes functional diversity would promote connectivity at the same time. Attention should also be put on small and isolated stands showing substantial reductions in resilience. Due to their poor connectivity, and therefore lower availability of seeds and traits from neighbor stands, such small forest patches are more sensitive to severe disturbance (Laurence and Curran 2008, Lloren et al. 2020). Small forest patches in rural landscapes, however, are fundamental for biodiversity conservation and for the delivery of a number of ecosystem services (Lindenmayer 2019, Valdés et al. 2020).

\section{Current management is not effective in promoting forest resilience}

In terms of forest biomass, species composition and resilience indicators, the differences between current management (BAU) and no management (CONTROL) were marginal. BAU further promoted northern hardwoods dominance and exotic conifers, such as Norway spruce, which is planted in pure stands for timber. Silvicultural activities are not very intense in the target landscape, aimed mainly at perpetuating current species 
composition and at maintaining the dominance of the most economically productive species (AFBF 2015). Planting is done to replace species that are currently in place (pines, spruce, maples) and silvicultural guidelines do not explicitly include the diversification of response traits and the establishment of plantations for goals other than timber production or habitat preservation (i.e., not for functional connectivity). Species with a southern distribution, which are considered more adapted to future climate (e.g., red oak, black cherry), have been planted only sporadically so they were excluded from the list of simulated species (see Appendix S1 and AFBF 2018). Although the enhancement of resilience of forest stands to climate change was indicated as being among the objectives of the sustainable forest management guidelines (AFBF 2015), our results show that under current management practices, forests in this region will likely become more homogeneous, less functionally diverse and less functionally connected, especially under high anthropogenic emissions. The decline of functional diversity and connectivity will likely make these forest landscapes less resilient to potential disturbances and future global change (Trumbore et al. 2015). This corroborates our third hypothesis that current management practices are not suitable for fostering forest resilience in an uncertain future. These results are in line with studies carried out in several regions of the world, indicating that current management practices are not appropriate to cope with challenges at local and regional scales (Creutzburg et al. 2017, Mina et al. 2017, Ibáñez et al. 2019) and that only substantial shifts in forest practices might be effective in promoting resilience under rapid climate and global change (Duveneck and Scheller 2016, Lucash et al. 2017). In the case of fragmented landscapes, maintaining species and traits diversity has been shown to be key for ecosystem functioning, particularly under a changing climate (Ratcliffe et al. 2017, Hertzog et al. 2019). Under BAU, our forest patches will likely lose important tree species that could play an important role in maintaining the resilience to future known and unknown disturbances. This highlights the need for a more active and thoughtful approach to forest management to maintain the resources and services that the forests provide (Millar et al. 2014, Fischer 2018).

\section{Limitations and future research avenues}

We applied LANDIS-II, a robust landscape model that has been tested in many studies throughout North America (Gustafson et al. 2015, Boulanger et al. 2017, Duveneck et al. 2017) and parameterized with a large data set of environmental and forest data, in the target landscape (Appendix S1). Moreover, we used the most mechanistic succession extension of LANDIS, PnETSuccession, to directly incorporate climate change effects, $\mathrm{CO}_{2}$ fertilization, water stress and ecophysiological factors on forest dynamics (de Bruijn et al. 2014,
Duveneck and Thompson 2017, McKenzie et al. 2019). Owing to its ability to capture processes at stand and landscape scales, we are confident that LANDIS-II with PnET-Succession provided us with robust projections useful for an assessment at multiple spatial scales. As for any process-based model, our calibration and simulations did not include every ecophysiological process, and there is always a degree of uncertainty behind landscape initialization, climate scenarios, model parameters, and the simulated species dynamics. For example, the too rapid decline of boreal pioneers might have been due to uncertainty in PnET species parameters (McKenzie et al. 2019) and expected responses in terms of forest types for the different scenarios.

In the present study, the disturbance scenario reflects our best knowledge of current disturbance agents. It was out of our scope to simulate scenarios of potential unknown disturbances, or specific disturbance agents (e.g., emerald ash borer Agrilus planipennis and other insect outbreaks, hurricanes, fire) and their spatial spread, but this would be recommended for consideration in further research. Also, we did not simulate plantation and enrichment with other species from outside the landscape, such as assisted migration or climate-suitable planting as a measure to increase functional diversity (Duveneck and Scheller 2015) or land-use change (Thompson et al. 2011).

Furthermore, there are limitations that must be acknowledged related to the functional network approach. First, using a different threshold in hectares to define forest patches may lead to different network structures and therefore different results. Second, we did not use a buffer zone outside the landscape or the five management areas (a $5-\mathrm{km}$ buffer outside the region was tested, resulting in minimal variations of the resilience indicators). Third, we only considered forest and nonforest; different land-use types between forest patches (e.g., crop, urban, water, or shrubland) may impact differently the ability to disperse seed, that is, functional connectivity, at multiple scales. Fourth, we assumed that having high connectivity was positively related to resilience. Although this was proven to be the case in our target region (Craven et al. 2016), in different landscapes high connectivity may negatively affect resilience by spreading disturbances faster, such as invasive species or fire (Turner et al. 1989). We suggest further studies to focus on simulating specific disturbance scenarios and assessing optimal levels of connectivity in relation to landscape structure. Also, other network properties could be investigated, such as node centrality and modularity; their use could allow us to better identify the portions of landscapes that should be given priority for intervention and to compare network topologies improving the assumptions made to build and analyze the network (Oldham et al. 2019). Lastly, in this study we applied a loosely coupled meta-modeling approach (i.e., we built and analyzed the functional network from model outputs). Despite the usefulness of our novel 
approach, we highly recommend continued development of a direct coupling approach (i.e., feedback loop from the network to the model). This would allow an interactive simulation of management scenarios based on network features.

\section{CONCLUSIONS}

Landscape dynamic modeling coupled with network analysis and functional diversity methods is a valuable approach for evaluating forest management adaptations to increase forest resilience to global change. In the northern temperate forest transition zone, climate change will likely promote forest productivity; combined with natural disturbances, it will also favor growth and dominance of heat-adapted deciduous species at the expense of boreal species. This would result in a loss in functional diversity and connectivity at the landscape level, which would hamper forest landscape resilience in the long term. The variations in our results depending on the spatial scale used also highlight the need for multi-scale assessments when evaluating future scenarios in fragmented forest landscapes.

Finally, our findings confirm that current management strategies are not suitable for counteracting the negative impacts of environmental changes and maintain forest resilience. Indeed, forestry may need to be more innovative, vigorous, and proactive than conventional silvicultural regimes. Depending on the landscape context and fragmentation intensity, this may include implementing coordinated landscape-level initiatives for enrichment planting to foster functional diversity or establishing mixed-species plantations to strategically enhance functional connectivity.

\section{AcKnowledgments}

This work has been supported by a grant to M. Mina from the Swiss National Science Foundation (project n.175101) and by funding to N. Aquilué and M. Mina from the Canada Research Chair in Forest Resilience to Global Changes attributed to C. Messier. The authors are grateful to Melanie Desrochers and Daniel Lesieurs for assistance in preparing spatial and inventory data; to Veronique Lalonde, Leslie Brandt, and Stephen Matthews for information on factor scores for the disturbance scenario; to Travis Logan at the Ouranos Consortium for the climate change scenarios; and to the Forestry Agency of Bois-Francs for information on forest management in the region. We also thank Alain Paquette for the computational facilities of his lab. Thanks to two anonymous reviewers for helpful comments that improved the quality of the paper. Authors' contributions: M. Mina, C. Messier, and N. Aquilué conceived the aims of the research; M. Mina parameterized the model, performed simulations, and analyzed outputs with support from M. Duveneck and N. Aquilué; N. Aquilué prepared the biophysical inputs for the simulation model and built the tools for analyzing the landscape as a functional network; M. Mina led the writing of the manuscript. M, Mina, C. Messier, M. Duveneck, M.-J. Fortin, and N. Aquilué structured the study, interpreted results, critically revised the drafts, and gave final approval.

\section{Literature Cited}

Aber, J. D., S. V. Ollinger, C. A. Federer, P. B. Reich, M. L. Goulden, D. W. Kicklighter, J. M. Melillo, and R. G. Lathrop Jr. 1995. Predicting the effects of climate change on water yield and forest production in the northeastern United States. Climate Research 05:207-222.

AFBF. 2015. Plan de protection et de mise en valeur des forêts privées du Centre-du-Québec. Agence forestière des BoisFrancs https://www.afbf.qc.ca/PPMV.aspx

AFBF. 2018. Rapport Annuel 2018-2019. Agence Forestière des Bois-Francs https://www.afbf.qc.ca/DbImages/Docume nts/Rapport $\% 20$ Annuel $\% 202018-2019$.pdf

Anderegg, W. R. L., et al. 2015. Tree mortality from drought, insects, and their interactions in a changing climate. New Phytologist 208:674-683.

Aquilué, N., É. Filotas, D. Craven, M.-J. Fortin, L. Brotons, and C. Messier. 2020. Evaluating forest resilience to global threats using functional response traits and network properties. Ecological Applications 30:e2095.

Arora, V. K., and G. J. Boer. 2010. Uncertainties in the 20th century carbon budget associated with land use change. Global Change Biology 16:3327-3348.

Aubin, I., et al. 2016. Traits to stay, traits to move: a review of functional traits to assess sensitivity and adaptive capacity of temperate and boreal trees to climate change. Environmental Reviews 24:164-186.

Aubin, I., C. Messier, S. Gachet, K. Lawrence, D. McKenney, A. Arseneault, W. Bell, L. De Grandpré, B. Shipley, and J. Ricard 2012. TOPIC-traits of plants in Canada. Natural Resources Canada, Canadian Forest Service, Sault Ste. Marie, Ontario, Canada. http://www.nrcan.gc.ca/forests/resea rch-centres/glfc/20303

Barrat, A., M. Barthélemy, R. Pastor-Satorras, and A. Vespignani. 2004. The architecture of complex weighted networks. Proceedings of the National Academy of Sciences USA 101:3747-3752.

Barton, A. M., and W. S. Keeton. 2018. Ecology and recovery of eastern old-growth forests. Island Press, Washington, D.C., USA.

Beller, E. E., E. N. Spotswood, A. H. Robinson, M. G. Anderson, E. S. Higgs, R. J. Hobbs, K. N. Suding, E. S. Zavaleta, J. L. Grenier, and R. M. Grossinger. 2018. Building ecological resilience in highly modified landscapes. BioScience 69:80-92.

Biswas, S. R., and A. U. Mallik. 2010. Disturbance effects on species diversity and functional diversity in riparian and upland plant communities. Ecology 91:28-35.

Boucher, D., Y. Boulanger, I. Aubin, P. Y. Bernier, A. Beaudoin, L. Guindon, and S. Gauthier. 2018. Current and projected cumulative impacts of fire, drought, and insects on timber volumes across Canada. Ecological Applications 28:12451259.

Boulanger, Y., A. R. Taylor, D. T. Price, D. Cyr, E. McGarrigle, W. Rammer, G. Sainte-Marie, A. Beaudoin, L. Guindon, and N. Mansuy. 2017. Climate change impacts on forest landscapes along the Canadian southern boreal forest transition zone. Landscape Ecology 32:1415-1431.

Brandt, L. A., A. D. Lewis, L. Scott, L. Darling, R. T. Fahey, L. Iverson, D. J. Nowak, A. R. Bodine, A. Bell, and S. Still.2017. Chicago Wilderness region urban forest vulnerability assessment and synthesis: a report from the Urban Forestry Climate Change Response Framework Chicago Wilderness pilot project. https://www.nrs.fs.fed.us/pubs/54128 Camarero, J. J., J. M. Olano, and A. Parras. 2010. Plastic bimodal xylogenesis in conifers from continental Mediterranean climates. New Phytologist 185:471-480. 
Contosta, A. R., et al. 2019. Northern forest winters have lost cold, snowy conditions that are important for ecosystems and human communities. Ecological Applications 29:e01974.

Correia, D. L. P., F. Raulier, M. Bouchard, and É. Filotas. 2018. Response diversity, functional redundancy, and postlogging productivity in northern temperate and boreal forests. Ecological Applications 28:1282-1291.

Craven, D., E. Filotas, V. A. Angers, and C. Messier. 2016. Evaluating resilience of tree communities in fragmented landscapes: linking functional response diversity with landscape connectivity. Diversity and Distributions 22:505-518.

Creutzburg, M. K., R. M. Scheller, M. S. Lucash, S. D. LeDuc, and M. G. Johnson. 2017. Forest management scenarios in a changing climate: trade-offs between carbon, timber, and old forest. Ecological Applications 27:503-518.

Csardi, G., and T. Nepusz. 2006. The igraph software package for complex network research. InterJournal Complex Systems: 1695 .

Dale, M. R. T., and M. J. Fortin. 2010. From graphs to spatial graphs. Annual Review of Ecology, Evolution, and Systematics 41:21-38.

de Bruijn, A., E. J. Gustafson, B. R. Sturtevant, J. R. Foster, B. R. Miranda, N. I. Lichti, and D. F. Jacobs. 2014. Toward more robust projections of forest landscape dynamics under novel environmental conditions: Embedding PnET within LANDIS-II. Ecological Modelling 287:44-57.

Delmas, E., et al. 2019. Analysing ecological networks of species interactions. Biological Reviews 94:16-36.

Dupuis, S., D. Arseneault, and L. Sirois. 2011. Change from pre-settlement to present-day forest composition reconstructed from early land survey records in eastern Québec, Canada. Journal of Vegetation Science 22:564-575.

Duveneck, M. J., and R. M. Scheller. 2015. Climate-suitable planting as a strategy for maintaining forest productivity and functional diversity. Ecological Applications 25:1653-1668.

Duveneck, M. J., and R. M. Scheller. 2016. Measuring and managing resistance and resilience under climate change in northern Great Lake forests (USA). Landscape Ecology 31:669-686.

Duveneck, M. J., and J. R. Thompson. 2017. Climate change imposes phenological trade-offs on forest net primary productivity. Journal of Geophysical Research: Biogeosciences 122:2298-2313.

Duveneck, M. J., J. R. Thompson, E. J. Gustafson, Y. Liang, and A. M. G. de Bruijn. 2017. Recovery dynamics and climate change effects to future New England forests. Landscape Ecology 32:1385-1397.

Dymond, C. C., S. Tedder, D. L. Spittlehouse, B. Raymer, K. Hopkins, K. McCallion, and J. Sandland. 2014. Diversifying managed forests to increase resilience. Canadian Journal of Forest Research 44:1196-1205.

ECCA. 2019. Environment and Climate Change Canada, Government of Canada. https://www.canada.ca/en/environ ment-climate-change.html

Elmqvist, T., C. Folke, M. Nyström, G. Peterson, J. Bengtsson, B. Walker, and J. Norberg. 2003. Response diversity, ecosystem change, and resilience. Frontiers in Ecology and the Environment 1:488-494.

Fahey, R. T., et al. 2018. Shifting conceptions of complexity in forest management and silviculture. Forest Ecology and Management 421:59-71.

Fischer, A. P. 2018. Forest landscapes as social-ecological systems and implications for management. Landscape and Urban Planning 177:138-147.

Fisichelli, N. A., L. E. Frelich, and P. B. Reich. 2014. Temperate tree expansion into adjacent boreal forest patches facilitated by warmer temperatures. Ecography 37:152-161.
Fontes, L., J. D. Bontemps, H. Bugmann, M. Van Oijen, C. Gracia, K. Kramer, M. Lindner, T. Rotzer, and J. P. Skovsgaard. 2010. Models for supporting forest management in a changing environment. Forest Systems 19:8-29.

Foster, D. R., G. Motzkin, and B. Slater. 1998. Land-use history as long-term broad-scale disturbance: regional forest dynamics in central New England. Ecosystems 1:96-119.

Frank, A., G. T. Howe, C. Sperisen, P. Brang, J. B. S. Clair, D. R. Schmatz, and C. Heiri. 2017. Risk of genetic maladaptation due to climate change in three major European tree species. Global Change Biology 23:5358-5371.

Gauthier, S., P. Bernier, T. Kuuluvainen, A. Z. Shvidenko, and D. G. Schepaschenko. 2015. Boreal forest health and global change. Science 349:819-822.

Girardin, M. P., E. H. Hogg, P. Y. Bernier, W. A. Kurz, X. J. Guo, and G. Cyr. 2016. Negative impacts of high temperatures on growth of black spruce forests intensify with the anticipated climate warming. Global Change Biology 22:627-643.

Gustafson, E. J., A. M. G. De Bruijn, R. E. Pangle, J.-M. Limousin, N. G. McDowell, W. T. Pockman, B. R. Sturtevant, J. D. Muss, and M. E. Kubiske. 2015. Integrating ecophysiology and forest landscape models to improve projections of drought effects under climate change. Global Change Biology 21:843-856.

Gustafson, E. J., S. R. Shifley, D. J. Mladenoff, K. K. Nimerfro, and H. S. He. 2000. Spatial simulation of forest succession and timber harvesting using LANDIS. Canadian Journal of Forest Research 30:32-43.

Halofsky, J. E., D. L. Peterson, K. L. Metlen, M. G. Myer, and V. A. Sample. 2016. Developing and implementing climate change adaptation options in forest ecosystems: a case study in Southwestern Oregon, USA. Forests 7:268.

Hertzog, L. R., et al. 2019. Forest fragmentation modulates effects of tree species richness and composition on ecosystem multifunctionality. Ecology 100:e02653.

Hof, A. R., C. C. Dymond, and D. J. Mladenoff. 2017. Climate change mitigation through adaptation: the effectiveness of forest diversification by novel tree planting regimes. Ecosphere 8:e01981.

Housset, J. M., M. P. Girardin, M. Baconnet, C. Carcaillet, and Y. Bergeron. 2015. Unexpected warming-induced growth decline in Thuja occidentalis at its northern limits in North America. Journal of Biogeography 42:1233-1245.

Ibáñez, I., K. Acharya, E. Juno, C. Karounos, B. R. Lee, C. McCollum, S. Schaffer-Morrison, and J. Tourville. 2019. Forest resilience under global environmental change: Do we have the information we need? A systematic review. PLoS ONE 14:e0222207.

IPCC. 2013. Climate change 2013: The physical science basis. Contribution of Working Group I to the Fifth Assessment Report of the Intergovernmental Panel on Climate Change. Cambridge University Press, Cambridge, UK.

Keenan, R. J. 2015. Climate change impacts and adaptation in forest management: a review. Annals of Forest Science 72:145-167.

Laliberte, E., et al. 2010. Land-use intensification reduces functional redundancy and response diversity in plant communities. Ecology Letters 13:76-86.

Laliberté, E., and P. Legendre. 2010. A distance-based framework for measuring functional diversity from multiple traits. Ecology 91:299-305.

LaPoint, S., N. Balkenhol, J. Hale, J. Sadler, and R. van der Ree. 2015. Ecological connectivity research in urban areas. Functional Ecology 29:868-878.

Laurence, W. F., and T. J. Curran. 2008. Impacts of wind disturbance on fragmented tropical forests: A review and synthesis. Austral Ecology 33:399-408. 
Lindenmayer, D. 2019. Small patches make critical contributions to biodiversity conservation. Proceedings of the National Academy of Sciences USA 116:717-719.

Lloren, J. I., L. Fahrig, J. R. Bennett, T. A. Contreras, and J. L. McCune. 2020. The influence of landscape context on shortand long-term forest change following a severe ice storm. Journal of Ecology 108:224-238.

Lucash, M. S., R. M. Scheller, E. J. Gustafson, and B. R. Sturtevant. 2017. Spatial resilience of forested landscapes under climate change and management. Landscape Ecology 32:953-969.

Marshall, I. B., C. A. S. Smith, and C. J. Selby. 1996. A national framework for monitoring and reporting on environmental sustainability in Canada. Pages 25-38 in Global to local: ecological land classification. Springer Netherlands, Thunderbay, Ontario, Canada.

Martin-Benito, D., and N. Pederson. 2015. Convergence in drought stress, but a divergence of climatic drivers across a latitudinal gradient in a temperate broadleaf forest. Journal of Biogeography 42:925-937.

Matthews, S. N., L. R. Iverson, A. M. Prasad, M. P. Peters, and P. G. Rodewald. 2011. Modifying climate change habitat models using tree species-specific assessments of model uncertainty and life history-factors. Forest Ecology and Management 262:1460-1472.

McKenzie, P. F., M. J. Duveneck, L. L. Morreale, and J. R. Thompson. 2019. Local and global parameter sensitivity within an ecophysiologically based forest landscape model. Environmental Modelling \& Software 117:1-13.

Messier, C., J. Bauhus, F. Doyon, F. Maure, R. Sousa-Silva, P. Nolet, M. Mina, N. Aquilué, M.-J. Fortin, and K. Puettmann. 2019. The functional complex network approach to foster forest resilience to global changes. Forest Ecosystems 6:21.

Messier, C., K. J. Puettmann, and K. D. Coates. 2013. Managing forests as complex adaptive systems : building resilience to the challenge of global change. First edition. Earthscan from Routledge, Abingdon, UK.

Messier, C., K. Puettmann, E. Filotas, and D. Coates. 2016. Dealing with non-linearity and uncertainty in forest management. Current Forestry Reports 2:150-161.

Messier, C., R. Tittler, D. D. Kneeshaw, N. Gélinas, A. Paquette, K. Berninger, H. Rheault, P. Meek, and N. Beaulieu. 2009. TRIAD zoning in Quebec: Experiences and results after 5 years. Forestry Chronicle 85:885-896.

MFFP. 2017. Inventaire écoforestier [Forest inventory, in French online]. Ministère des Forêts, de la Faune et des Parcs. https://mffp.gouv.qc.ca/les-forets/inventaire-ecoforestier/

Miles, P. D., and W. B. Smith. 2009. Specific gravity and other properties of wood and bark for 156 tree species found in North America. U.S. Department of Agriculture, Forest Service, Northern Research Station, Newtown Square, Pennsylvania, USA.

Millar, C. I., and N. L. Stephenson. 2015. Temperate forest health in an era of emerging megadisturbance. Science 349:823-826.

Millar, C. I., C. W. Swanston, and D. L. Peterson. 2014. Adapting to climate change. Pages 183-222 in D. L. Peterson, J. M. Vose, and T. Patel-Weynand, editors. Climate change and United States forests. Springer Netherlands, Dordrecht, The Netherlands.

Mina, M., H. Bugmann, T. Cordonnier, F. Irauschek, M. Klopcic, M. Pardos, and M. Cailleret. 2017. Future ecosystem services from European mountain forests under climate change. Journal of Applied Ecology 54:389-401.

Mitchell, M. G. E., E. M. Bennett, and A. Gonzalez. 2014. Forest fragments modulate the provision of multiple ecosystem services. Journal of Applied Ecology 51:909-918.
Mori, A. S., T. Furukawa, and T. Sasaki. 2013. Response diversity determines the resilience of ecosystems to environmental change. Biological Reviews 88:349-364.

Nabuurs, G.-J., P. Delacote, D. Ellison, M. Hanewinkel, L. Hetemäki, and M. Lindner. 2017. By 2050 the mitigation effects of EU forests could nearly double through climate smart forestry. Forests 8:484.

Niinemets, U., and F. Valladares. 2006. Tolerance to shade, drought, and waterlogging of temperate Northern Hemisphere trees and shrubs. Ecological Monographs 76:521-547.

Nock, C. A., R. Vogt, and B. Beisner. 2016. Functional traits. John Wiley \& Sons, Hoboken, New Jersey, USA.

Oldham, S., B. Fulcher, L. Parkes, A. Arnatkevičiūte, C. Suo, and A. Fornito. 2019. Consistency and differences between centrality measures across distinct classes of networks. PLoS ONE 14:e0220061.

Ouranos. 2015. Towards Adaptation. Summary of the Synthesis on Climate Change Knowledge in Quebec. Ouranos Montréal, Québec https://www.ouranos.ca/publication-scientif ique/SyntheseRapportfinal.pdf

Pavoine, S., J. Vallet, A.-B. Dufour, S. Gachet, and H. Daniel. 2009. On the challenge of treating various types of variables: application for improving the measurement of functional diversity. Oikos 118:391-402.

Pillar, V. D., C. C. Blanco, S. C. Müller, E. E. Sosinski, F. Joner, and L. D. S. Duarte. 2013. Functional redundancy and stability in plant communities. Journal of Vegetation Science 24:963-974.

Prasad, A., L. Iverson, S. Matthews, and M. Peters.2007. A climate change atlas for 134 forest tree species of the eastern United States [database]. http://www.nrs.fs.fed.us/atlas/tree

Puettmann, K. J., K. D. Coates, and C. C. Messier. 2009. A critique of silviculture: managing for complexity. Island Press, Washington, D.C., USA.

Puettmann, K. J., and J. C. Tappeiner. 2013. Multi-scale assessments highlight silvicultural opportunities to increase species diversity and spatial variability in forests. Forestry: An International Journal of Forest Research 87:1-10.

R Core Team. 2019. R: a language and environment for statistical computing. R Foundation for Statistical Computing, Vienna, Austria. http://www.R-project.org

Ratcliffe, S., et al. 2017. Biodiversity and ecosystem functioning relations in European forests depend on environmental context. Ecology Letters 20:1414-1426.

Raymond, P., A. D. Munson, J.-C. Ruel, and K. D. Coates. 2006. Spatial patterns of soil microclimate, light, regeneration, and growth within silvicultural gaps of mixed tolerant hardwood-white pine stands. Canadian Journal of Forest Research 36:639-651.

Ricotta, C., F. de Bello, M. Moretti, M. Caccianiga, B. E. L. Cerabolini, and S. Pavoine. 2016. Measuring the functional redundancy of biological communities: a quantitative guide. Methods in Ecology and Evolution 7:1386-1395.

Ricotta, C., A. Stanisci, G. C. Avena, and C. Blasi. 2000. Quantifying the network connectivity of landscape mosaics: a graph-theoretical approach. Community Ecology 1:89-94.

Saura, S., and L. Pascual-Hortal. 2007. A new habitat availability index to integrate connectivity in landscape conservation planning: Comparison with existing indices and application to a case study. Landscape and Urban Planning 83:91-103.

Scheller, R. M., J. B. Domingo, B. R. Sturtevant, J. S. Williams, A. Rudy, E. J. Gustafson, and D. J. Mladenoff. 2007. Design, development, and application of LANDIS-II, a spatial landscape simulation model with flexible temporal and spatial resolution. Ecological Modelling 201:409-419.

Seastedt, T. R., R. J. Hobbs, and K. N. Suding. 2008. Management of novel ecosystems: are novel approaches required? Frontiers in Ecology and the Environment 6:547-553. 
Seidl, R., et al. 2017. Forest disturbances under climate change. Nature Climate Change 7:395.

Seidl, R., C. S. Eastaugh, K. Kramer, M. Maroschek, C. Reyer, J. Socha, G. Vacchiano, T. Zlatanov, and H. Hasenauer. 2013. Scaling issues in forest ecosystem management and how to address them with models. European Journal of Forest Research 132:653-666.

Seidl, R., T. A. Spies, D. L. Peterson, S. L. Stephens, and J. A. Hicke. 2016. Searching for resilience: addressing the impacts of changing disturbance regimes on forest ecosystem services. Journal of Applied Ecology 53:120-129.

Shifley, S. R., H. S. He, H. Lischke, W. J. Wang, W. Jin, E. J. Gustafson, J. R. Thompson, F. R. Thompson, W. D. Dijak, and J. Yang. 2017. The past and future of modeling forest dynamics: from growth and yield curves to forest landscape models. Landscape Ecology 32:1307-1325.

Standish, R. J., et al. 2014. Resilience in ecology: Abstraction, distraction, or where the action is? Biological Conservation 177:43-51.

Thompson, I., B. Mackey, S. McNulty, and A. Mosseler. 2009. Forest resilience, biodiversity, and climate change. A synthesis of the biodiversity/resilience/stability relationship in forest ecosystems. Secretariat of the Convention on Biological Diversity, Montreal, Quebec, Canada. Technical Series no. 43, 67 pages.

Thompson, J. R., D. R. Foster, R. Scheller, and D. Kittredge. 2011. The influence of land use and climate change on forest biomass and composition in Massachusetts, USA. Ecological Applications 21:2425-2444.

Trumbore, S., P. Brando, and H. Hartmann. 2015. Forest health and global change. Science 349:814-818.
Turner, M. G., R. H. Gardner, V. H. Dale, and R. V. O'Neill. 1989. Predicting the spread of disturbance across heterogeneous landscapes. Oikos 55:121-129.

Urban, D., and T. Keitt. 2001. Landscape connectivity: a graph-theoretic perspective. Ecology 82:1205-1218.

Valdés, A., et al. 2020. High ecosystem service delivery potential of small woodlands in agricultural landscapes. Journal of Applied Ecology 57:4-16.

Vilà-Cabrera, A., L. Coll, J. Martínez-Vilalta, and J. Retana. 2018. Forest management for adaptation to climate change in the Mediterranean basin: A synthesis of evidence. Forest Ecology and Management 407:16-22.

Violle, C., M.-L. Navas, D. Vile, E. Kazakou, C. Fortunel, I. Hummel, and E. Garnier. 2007. Let the concept of trait be functional! Oikos 116:882-892.

Wang, W. J., H. S. He, F. R. Thompson, J. S. Fraser, and W. D. Dijak. 2017. Changes in forest biomass and tree species distribution under climate change in the northeastern United States. Landscape Ecology 32:1399-1413.

Weed, A. S., M. P. Ayres, and J. A. Hicke. 2013. Consequences of climate change for biotic disturbances in North American forests. Ecological Monographs 83:441-470.

Willig, M. R., and S. J. Presley. 2018. Biodiversity and Disturbance. Pages 45-51 in D. A. Dellasala, and M. I. Goldstein, editors. Encyclopedia of the Anthropocene. Elsevier, Oxford, UK.

Yachi, S., and M. Loreau. 1999. Biodiversity and ecosystem productivity in a fluctuating environment: The insurance hypothesis. Proceedings of the National Academy of Sciences USA 96:1463-1468.

\section{SUPPORTING INFORMATION}

Additional supporting information may be found online at: http://onlinelibrary.wiley.com/doi/10.1002/eap.2221/full

\section{Data Availability}

Data associated with this study are available from Zenodo: https://doi.org/10.5281/zenodo.3823195. 